\title{
Ejercitar al cuerpo: la gimnasia femenina en el Colegio de la Paz (Vizcaínas), $1875-1915^{*}$
}

\section{Exercising the Body: Female Gymnastics at Colegio de la Paz (Vizcaínas), 1875-1915}

\author{
Genevieve Galán Tamés** \\ (D) https://orcid.org/0000-0001-8097-4881 \\ Colegio de Historia, Facultad de Filosofía y Letras \\ Universidad Nacional Autónoma de México, México \\ ggalantames@gmail.com
}

Resumen: El artículo analiza la introducción de la gimnasia en el Colegio de la Paz y algunos aspectos vinculados a su implementación de 1875 a 1915. A partir del estudio de este espacio, el texto ahonda en ciertas condiciones de posibilidad históricas que permiten pensar la ejercitación corporal y la introducción de la educación física en México, dentro del espacio escolar. Vizcaí-

* Este texto forma parte del proyecto: "El 'gesto corrector': educación corporal en los colegios femeninos de la ciudad de México en la época moderna (1843-1921)". unAM. Programa de Becas Posdoctorales en la UNAM, becaria del Instituto de Investigaciones Históricas, asesorada por la doctora Susana Sosenski Correa.

** Doctora en Historia y Civilización, Escuela de Altos Estudios en Ciencias Sociales (eness), París, Francia. Profesora asociada "C" de tiempo completo en el Colegio de Historia, Facultad de Filosofía y Letras, UnAM. Agradezco a las responsables del Archivo Histórico José María Basagoiti Noriega, Vizcaínas, su valiosa orientación y apertura: María Eugenia Almaraz, Janet Toledo y a su directora, Ana Rita Valero. Esta investigación toma en consideración únicamente y en su mayoría, documentos de este archivo, así como obras que formaron parte de su biblioteca colegial en el siglo xix.

cómo citAR: Galán Tamés, G. (2021). Ejercitar al cuerpo: la gimnasia femenina en el Colegio de la Paz (Vizcaínas), 1875-1915. Secuencia (109), e1763. Dor: https://doi.org/10.18234/secuencia.v0i109.1763

cc $(1)$ Esta obra está protegida bajo una Licencia Creative Commons Atribución-NoComercial 4.0 Internacional. 
nas puede utilizarse como ilustración del proyecto que una elite profesional y política-comprometida con la educación de la mujer y la consolidación de la educación física, higiénica y moderna- buscó implementar como pauta general en los colegios del país. El texto apunta que la introducción de la gimnasia en el ámbito escolar implicó la gradual consolidación de un sistema de lectura y evaluación del movimiento del cuerpo. Asimismo, ofrece indicios de la formación de profesoras de gimnasia en un periodo en el que la educación física se estaba profesionalizando.

Palabras clave: gimnasia; higiene; educación física; cuerpo; Vizcaínas.

Abstract: The article analyzes the introduction of gymnastics into Colegio de la Paz and certain aspects related to its implementation from 1875 to 1915. Through the study of this space, the text delves into certain conditions of historical possibility that allow thinking about physical exercise and the introduction of physical education within Mexican schools. Colegio Vizcaínas can be used as an illustration of the project showing how a professional and political elite -committed to the education of women and the consolidation of physical, hygienic, and modern education-sought to implement it as a general guideline in the country's schools. The text points out that the introduction of gymnastics into the school environment entailed the gradual consolidation of a system for interpreting and evaluating the body's movement. It also provides evidence of the training of gymnastics teachers in a period when physical education was becoming more professional.

Keywords: body; physical education; gymnastics; hygiene; Vizcaínas.

Recibido: 24 de junio de 2019 Aceptado: 8 de junio de 2020

Publicado: 9 de febrero de 2021

A partir de finales del siglo XVIII - poco antes, poco después- las represen-
taciones en torno al funcionamiento del cuerpo humano se modificaron
paulatinamente. Gracias al desarrollo de la ciencia, la medicina y la anatomía
"modernas", entre otros saberes, el ejercicio físico comenzó a obtener signi- 
ficados distintos a los que poseía antaño y a ser valorado a partir de nuevos criterios fisiológicos y anatómicos. En este contexto la idea de la ejercitación física, como un hábito positivo para las sociedades, fue ganando terreno. A lo largo del siglo xix, la práctica de ejercicios físicos fue incorporada a los distintos proyectos educativos de las naciones con el fin de aumentar la salud corporal, mejorar las características físicas de los ciudadanos y contribuir a la formación moral e intelectual de los individuos.

Una de las primeras formas de ejercicios físicos que se difundió e implementó en el espacio escolar, con un carácter higiénico y pedagógico, fue la gimnasia o gimnástica. Según se explicaba, la gimnástica era la ciencia razonada de los movimientos del cuerpo y de su vínculo con los sentidos, la inteligencia, los sentimientos, las costumbres y el desarrollo de todas las facultades (Amorós, 1848, p. I). En este horizonte el ejercicio gimnástico fue considerado un arte anatómico fisiológico "necesario para la salud y el equilibrio de las razas y obligatorio en toda sociedad caritativa y civilizada que se preocupa de los problemas de la beneficencia y longevidad" (Fraguas, 1897, p. 2). Para el caso de México, Garrido (2016) señala que la gimnasia fue a lo largo del siglo XIX "la forma de ejercicio corporal más acabada y sistematizada que se practicó y enseñó" (pp. 26-27). Se pensaba que los ejercicios gimnásticos eran un método suave que con el tiempo lograrían robustecer el cuerpo de hombres, mujeres y niños: "preparando por este medio la base para los conocimientos morales que con posteridad se les inculcasen” (Borja, 1856, p. 4).

Con base principal en documentos del archivo histórico del colegio, este texto tiene como objetivo analizar la introducción de la gimnasia en el Colegio de la Paz (Vizcaínas), así como algunos aspectos vinculados a su implementación en el periodo que va de 1875 (año en el que se propone la creación de la cátedra) a 1915 (año en el que la cátedra es suspendida indefinidamente por decisión de las autoridades del Colegio, debido al agitado contexto que se vivía en la ciudad de México). A partir del estudio de este espacio busco entender algunas de las condiciones de posibilidad históricas que permitieron pensar antaño la ejercitación corporal y la introducción de la educación física en México. Por condiciones de posibilidad históricas me refiero a las circunstancias que en determinadas coyunturas sostienen la ocurrencia de ciertos hechos, ideas, pensamientos y prácticas, entre otros. ${ }^{1} \mathrm{~A}$ lo largo del

${ }^{1}$ Para pensar las "condiciones de posibilidad", remito al lector a la siguiente cita: "comprender [históricamente] no es esconderse en una ideología ni dar un apelativo cualquiera a lo 
texto ahondaré en los siguientes puntos: la instauración y desarrollo temporal de la clase, los profesores y los métodos de gimnasia, así como ciertos aspectos vinculados al aprendizaje gimnástico de las profesoras y alumnas.

Estudiar la introducción de la gimnasia en el espacio escolar podría parecer poco pertinente frente a la bibliografía que se ha abocado recientemente a la investigación del tema. ${ }^{2}$ Sin embargo, considero que el estudio que aquí desarrollo contribuye a articular grandes ejes temáticos -como lo son la educación, la higiene, la educación física y la historia del cuerpo- en espacios concretos. Parafraseando a Ginzburg (1997), la consideración de la pequeña escala (lo micro), es útil en el sentido que se propone como un modo complementario de captar el funcionamiento de representaciones y mecanismos más amplios, situados en un nivel macro. Se estudia un caso o un espacio particular para apreciar significados que podrían haber acabado por ser invisibles, o bien, porque pueden servir de ilustración general. Desde mi perspectiva, el Colegio de la Paz puede considerarse como un "espacio de experimentación historiográfica” de estos múltiples temas y problemas más amplios por dos motivos: a) su permanencia ininterrumpida en el panorama de las instituciones educativas del país, desde su apertura y a lo largo de los distintos periodos; $b$ ) su carácter vanguardista a nivel educativo durante la temporalidad que aquí se estudia.

El Colegio de la Paz -inaugurado originalmente con el nombre de Real Colegio de San Ignacio de Loyola en 1767, y popularmente conocido como

que permanece oculto. Comprender es tener que encontrar en la misma información histórica aquello que la vuelve pensable" (Certeau, 1993, p. 21)

${ }^{2}$ Para el caso de México sobresalen los estudios en torno a los deportes (entendidos como actividades físicas de competencia realizadas de manera secularizada, en las que impera la igualdad de condiciones para los competidores, la especialización de la disciplina y la racionalización de reglas, cuya finalidad es registrar y superar récords), especialmente a partir del porfiriato y a lo largo del siglo xx. Uno de los estudios que contribuye a introducir este tema en la historiografía mexicana es Beezley (2004). Con el objetivo de sistematizar los estudios en torno a la educación física en aras de ampliar el campo de estudio y no limitarlo sólo a los deportes, Garrido (2016) ha introducido el término "cultura física". Entendido como "el conjunto de ideas, prácticas y creencias respecto al ejercicio corporal que se expresan en determinada sociedad" (p. 12). En ese tenor más "amplio" (en el cual busca insertarse esta investigación), se destacan los siguientes estudios: Chávez (2015); Garrido (2014, 2016); Martínez Moctezuma (2011), por mencionar algunos. Desde una perspectiva similar, Saint Martin y Attali (2016) han propuesto asimismo el término de "actividad física" para estudiar las actividades propuestas en el espacio escolar que buscan ocuparse del desarrollo físico del cuerpo, sin limitarse únicamente a las prácticas deportivas. 
Vizcaínas-, logró consolidarse durante el porfiriato como uno de los colegios de niñas de mayor prestigio de la capital, gracias al gran interés y apoyo financiero que le brindó el gobierno de Díaz (Torres Septién, 1997, p. 80). ${ }^{3}$ Lo que vuelve significativo al Colegio en este periodo y para fines del presente estudio, es que en su interior reunió -en calidad de miembros de la junta directiva, profesores y médicos del establecimiento-a distinguidas figuras de la elite política y profesional de la época (véase cuadro 1), artífices de la modernidad porfiriana, comprometidos con el proyecto de una educación moderna e higiénica, y el avance y la consolidación de la educación física en México.

La junta directiva del Colegio (integrada por un presidente, tres vocales y un tesorero) sostenía reuniones periódicas y era la instancia encargada de velar por el buen funcionamiento del establecimiento en todos los aspectos (administrativos, financieros, educativos, etc.). Para apoyar la toma de decisiones en materia educativa, a finales del siglo xIX se creó una junta de profesores, conformada por los profesores y las profesoras del Colegio. Esta junta de profesores se reunía periódicamente en aras de discutir distintos aspectos vinculados a la enseñanza en el Colegio. Sus propuestas eran consideradas por la junta directiva para la toma de decisiones, junto con los informes del médico del establecimiento y el de las directoras de cada departamento.

Algunos de los personajes a los que me refiero y que tuvieron un papel importante en la toma de decisiones en el Colegio o como promotores de una educación corporal moderna e higiénica se mencionan en el cuadro $1 .{ }^{4}$

El Colegio de la Paz fue, en cierta medida y gracias a la labor de estos personajes, uno de los escaparates del proyecto higienista y pedagógico moderno. Por ende, es posible afirmar que este Colegio fue un laboratorio del proyecto de modernidad que buscó implantarse en México durante este

${ }^{3}$ El Colegio, fundado y patrocinado por la Cofradía de Aránzazu, abrió sus puertas en 1767. En la segunda mitad del siglo xIx cambió su nombre a Colegio de la Paz (en el siglo xx volverá a retomar su nombre original). En el periodo que aquí nos ocupa el Colegio se dividía en tres departamentos: el departamento de internas (conformado por las niñas y jóvenes, así como por las profesoras, que habitaban el Colegio y se educaban en este); el departamento de externas (conformado por las niñas y jóvenes que se educaban en el Colegio, pero que no habitaban en este); y el departamento de asilo (conformado por mujeres que seguían habitando el Colegio aunque ya no se educaban en él). En este texto, me centró únicamente en el departamento de internas. Para ahondar más en la historia del Colegio, consúltense los clásicos, Muriel (1987) y Olavarría (1889). De reciente aparición, véase a modo de orientación, Galván Lafarga (2017).

${ }^{4}$ Debido a que hablaré de ellos más adelante, en este cuadro no se menciona a los profesores de gimnasia, cuya labor también es fundamental. 


\section{Cuadro 1. Miembros de la junta directiva, profesores y médicos del establecimiento}

Figura

Joaquín Eguía Lis

(1833-1917)

Alfredo Chavero

(1841-1906)
Destacado profesor y jurista. Nombrado por

Justo Sierra rector de la

Universidad Nacional de

México.

Político, historiador y dramaturgo. Fue regidor del Ayuntamiento de la ciudad de México y miembro de la Academia Mexicana de la Lengua.

Sebastián Camacho y Senador e importante Zulueta

(1822-1915)

$$
\begin{aligned}
& \text { empresario ferrocarrilero. } \\
& \text { Miembro de la asocia- } \\
& \text { ción literaria El Ateneo } \\
& \text { Mexicano. }
\end{aligned}
$$

Enrique de Olavarría y Ferrari (1844-1919)

Eduardo Liceaga (1839-1920) y diputado federal. Cola-
Escritor, periodista, docent boró en varias publicaciones y periódicos.

Destacado médico e higienista. Fue presidente del Consejo Superior de Salubridad, director del Hospital de Maternidad e Infancia, presidente de la Academia Nacional de Medicina y director de la Escuela Nacional de Medicina.
Papel en el Colegio

Presidente de la junta directiva de 1877 a 1885.

Presidente de la junta directiva de 1885 a 1889.

Presidente de la junta directiva de 1899 a 1914.

Tesorero-administrador a partir de 1885 .

Consejero y vocal de la junta directiva de ca. 1880 a ca.1915. Dictó una serie de conferencias a las alumnas y maestras sobre higiene entre 1912 y 1915. Participó activamente en la supervisión higiénica de todos los trabajos y remodelaciones en el Colegio durante esta época. 
Figura

Luis E. Ruiz

(1853-1915)

gnacio Martínez del

Villar

Manuel Soriano

(1837-1927)
Médico higienista. Fue miembro de la Academia Nacional de Medicina, del Consejo Superior de Instrucción Pública y vocal del Consejo Superior de Salubridad.

Papel en el Colegio

Presidente de la junta de profesores de 1890 a 1912 . Catedrático en Vizcaínas, desde 1886, de las clases de: física y química, historia natural, fisiología, pedagogía e higiene. Fue autor de diversos textos que formaron parte de la biblioteca del Colegio y que se utilizaron también como libros de texto.

Vocal de la junta directiva en gía de la Escuela Nacional Preparatoria.

1877. Catedrático en el Colegio, de 1878 a 1902, de las materias: fisiología e higiene y medicina doméstica. Su obra bibliográfica fue enormemente utilizada, pues fungió como libro de texto mientras él fue profesor.

Médico cirujano. Profesor Médico del establecimiento de de la facultad de medicina y secretario de la Academia Nacional de Medicina. 1890 hasta aproximadamente 1927. A su cargo estaba la inspección médica de todas las habitantes de Vizcaínas.

Fuentes: Archivo Histórico José María Basagoiti Noriega del Colegio de las Vizcaínas, México; Garibay y Teixidor (1964); Mörner (2001), y Olavarría (1889).

periodo. De ahí la representatividad de este plantel escolar para pensar este tema en particular. Recordemos que en los años estudiados la ciudad de México buscó convertirse en "un escaparate del orden, el progreso, la limpieza y la salubridad" en aras de mostrar el grado de civilización y modernidad del país (Agostoni, 2002, p. 2). Es posible afirmar que la gimnasia, como parte de un proyecto de educación corporal e higiénica más grande, fue una de las 
pruebas ineludibles de esta modernidad. La educación en este periodo, no lo olvidemos, era una de las bases del tan anhelado progreso.

\section{LA CLASE DE GIMNASIA DE 1875 A 1915}

El 29 de diciembre de 1875 Manuel Castilla Portugal -vocal de la junta directiva del Colegio- presentó un proyecto para establecer una clase de gimnasia en el plantel. Es imperativo vincular brevemente la propuesta de Castilla con algunos de los esfuerzos previos en el país por introducir la educación física en los planteles escolares. Uno de estos esfuerzos y que pretendió tener un carácter nacional fue, por ejemplo, el del ministro Manuel Baranda mediante el Plan general de instrucción pública publicado en 1843. En el plan de Baranda se ahonda en la idea de que una de las bases "racionales y eficaces" de la educación para todo "hombre recomendable" debe ser la educación física y moral de los estudiantes (Ríos y Rosas, 2011, p. 35). Empero, la continuidad de los proyectos educativos nacionales, como bien se ha estudiado, se vio afectada debido a la convulsa situación política que atravesó el país a lo largo del siglo XIX. En 1861 nuevamente encontramos otra clara alusión a los ejercicios gimnásticos en el proyecto educativo del Estado, con la publicación del Decreto del gobierno sobre arreglo de instrucción pública, publicado durante el gobierno de Benito Juárez. Este decreto estipulaba que debían establecerse, en todas las escuelas, clases de ejercicios gimnásticos y de esgrima. Destaca además que en esta ocasión se hace clara alusión a la educación corporal de las niñas, al indicarse que los ejercicios gimnásticos debían quedar comprendidos como parte del currículo "normal" para las escuelas de niñas (Meneses Morales, 1998, pp. 183-184). Estos breves ejemplos permiten vislumbrar la importancia que la gimnasia comenzó a adquirir como parte del currículo de una educación ideada por el Estado. Para el caso del Colegio, con base en la documentación que he revisado, no he encontrado, sin embargo, indicios claros de que se impartiera una clase similar antes de 1875 , a pesar de estos esfuerzos previos con carácter nacional. De modo que la propuesta de Castilla es la primera propuesta formal al interior del Colegio que buscó introducir la educación física.

Retomando, observamos que después de discutida la propuesta y tras algunas modificaciones, la junta directiva la aprobó el 19 de enero de 1876. Así, se estableció la obligatoriedad de la clase de gimnasia para todas las alumnas menores de 21 años. Esta debía impartirse por lo menos tres veces a la 
semana, después de las cinco de la tarde y en el espacio que el profesor creyese más adecuado, mientras se esperaba la creación del jardín del Colegio. El sistema por adoptarse debía ser el de "autogimnasia", pudiendo: "mezclar algunos ejercicios de mediana fuerza que no causen mal a las alumnas". Sólo las alumnas afectadas por alguna enfermedad y con el aval del médico del Colegio estaban exentas de asistir a la clase. La Junta nombró además a Joaquín Noreña (i?-1896), destacado profesor de gimnasia de la época, instructor de dicha clase; y estableció la suma única de 100 pesos para la compra de todos los aparatos necesarios y su colocación. ${ }^{5}$

Salvo lo que se recopila en el Acta que deja constancia de la aprobación de la clase, la propuesta original de Castilla no se conserva, de modo que sólo podemos inferir los motivos que lo llevaron a proponer dicha cátedra y los argumentos que esgrimió para señalar su importancia. Con base en la investigación de Garrido (2016) y en los breves ejemplos que mencioné con anterioridad, observamos que la propuesta de Castilla se inserta en un ambiente en el que la implementación de la gimnasia en las escuelas buscaba ser la norma, a pesar de que en la praxis permaneciera la mayoría de las veces en una excepción. En este contexto, la promoción y práctica de ejercicios corporales quedó comprendida dentro de las preocupaciones de la higiene escolar (Staples, 2008, pp. 32-38) y la llamada "educación integral" (Gil Mendoza, 2010, pp. 45-46). Desde este horizonte se hacía énfasis en la idea de que una población enferma y sin sentido de la higiene era considerada una sociedad atrasada y poco civilizada (Agostoni, 2001, pp. 73-93). La necesidad de formar individuos robustos y sanos mediante la ejercitación física adquiere un cariz relevante en esta coyuntura.

A la par, es interesante notar que la propuesta de Castilla se presenta meses después de que el ministro de Instrucción Pública, José Díaz Covarrubias, publicara La instrucción pública en México. En este texto, Díaz Covarrubias (1875) se queja del estado en el que se encuentra la educación en México y realiza un diagnóstico a propósito de algunos vacíos de alta importancia que observa en las escuelas. Los vacíos a los que alude se vinculan a la falta absoluta de toda educación corporal de los niños, comprendiendo a la educación física e higiénica, mismas que en la época iban de la mano.

${ }^{5}$ Actas de juntas celebradas de enero de 1875 a diciembre de 1883. Estante 4, tabla v, vol. 12, f. 31, verso y 33, fs. 18663-18665. Archivo Histórico José María Basagoiti Noriega (en adelante AнJMBN), México. 
En la mayoría de los textos el objeto de la gimnasia es en un primer momento el cuerpo del hombre y sólo secundariamente el de la mujer. Lo que lleva a abrir la pregunta ipor qué esta clase debió ser importante para el caso de los colegios de niñas? y ¿cómo podían estos cuerpos beneficiarse con el trabajo de la gimnasia? En ese sentido, López Sánchez (2006) argumenta que el desarrollo del pensamiento científico moderno no cambió sustancialmente la concepción social que se tenía de los cuerpos de las mujeres durante el siglo xix e inicios del xx. López señala que los "médicos a través de sus discursos reforzaron la imagen femenina como un ser dependiente, débil, emocionalmente inestable y altamente propenso a enfermar" (p. 16). Ciertamente, la particularidad fue que a partir de la modernidad la "condición biológica" comenzó a ser el cimiento de los argumentos "científicos" en torno a los cuerpos de los individuos y sus diferencias. Y la "ciencia médica" el discurso del que emanaron los discursos legítimos y dominantes para pensar los cuerpos y su funcionamiento.

Esbozando algunos argumentos, observamos que el cuerpo de la mujer, a diferencia del hombre, era un cuerpo que por sus "funciones fisiológicas particulares" (menstruación, gestación y lactancia) se agotaba rápidamente. A pesar de que paradójicamente eran también cuerpos que tendían a una mayor insensibilidad física (y moral) y a un mayor umbral del dolor. Lo anterior era el origen de un sinfín de padecimientos físicos y morales (López Sánchez, 2008). No es de extrañar que ante un cuerpo tan endeble como era el femenino, algunos tratados de gimnasia le asignaran un espacio para pensar y describir los ejercicios más a propósito para su constitución. Uno de los argumentos centrales de la promoción de la gimnasia fue que esta era útil a todas las constituciones, edades y sexos. José Sánchez, uno de los profesores de gimnasia del Colegio, señalaba que el cuerpo femenino era el más débil y por ende el que más fortaleza necesitaba (Sánchez, 1884, p. 79). La vida sedentaria de la mujer (a la que por naturaleza se inclinaba) reclamaba el ejercicio corporal como un medio para equilibrar sus fuerzas vitales y auxiliarla en su salud. Al entrar en la pubertad, además, el ejercicio corporal se volvía muy útil para evitarle "dolencias que son un obstáculo a su desarrollo" (Lladó, 1868, pp. 124-125). Sumado a los argumentos terapéuticos, el cuerpo femenino se beneficiaba en términos estéticos y morales con la práctica de la gimnasia, puesto que esta aportaba a las formas de la mujer "belleza" y "delicadeza", aunada a cierta robustez y vigor adecuados a su constitución (y necesarios para auxiliarla en sus funciones de madre y ama de casa). En términos morales el ejercicio tenía enorme trascendencia, pues le ayudaba a combatir, entre otras 
cosas, el tan perjudicial ocio (tan propio siempre de este sexo) y la irritabilidad cerebral o nerviosa.

Con base en lo esbozado, puede entenderse por qué teóricamente la educación -que aquí calificaremos como "corporal"- de la mujer cobre relevancia en el espacio escolar. Esta importancia se da no sólo en términos de salud e higiene privada, sino también en términos sociales, ya que serán estos cuerpos los encargados de parir individuos robustos y sanos, y los responsables -como madres y mujeres- de la primera educación corporal de los futuros ciudadanos (no hay que olvidar que estas son las encargadas del cuidado de los cuerpos: de nutrirlos, de asearlos, de fomentar e implementar ejercicios físicos en la primera infancia, de enseñar hábitos higiénicos, etc.). La educación corporal e higiénica de la futura madre es hasta cierto punto la extensión de la educación corporal de su futuro hijo. En este periodo los médicos higienistas pensaban que

para fomentar una verdadera cultura de la higiene, era menester enseñar los principios y preceptos de la higiene a la población. [...] los profesionales de la medicina reconocían que para esta empresa requerían contar con el apoyo de diversos grupos sociales, y en particular con la participación de la madre de familia. Se pensaba que la madre de familia era una educadora por naturaleza y que era precisamente ella quien podría ayudar o transformar las formas de vida de los mexicanos higiénica o positivamente. La educación higiénica de la mujer se convirtió en una de las principales preocupaciones del gremio médico durante el cambio de siglo (Agostoni, 2002, p. 4).

Algunos textos gimnásticos hacen eco precisamente de esto último. El gimnasta Sánchez subrayaba el hecho de que la fisiología había demostrado: "la parte que corresponde a la madre en las buenas generaciones, de modo que inútilmente tendréis hombres robustos si las mujeres no lo fueron también” (Sánchez, 1884, p. 16).

$\mathrm{Al}$ interior del Colegio contrasta que, a pesar de los beneficios que la gimnasia aportaba a la educación de las colegialas, esta cátedra tuvo, en un primer momento, un desarrollo un tanto accidentado según dejan entrever los documentos con los que contamos para recrear esta historia. Centrémonos por lo pronto en la implementación y el desarrollo de la cátedra a lo largo de los años aquí estudiados. Observamos que en ciertos periodos de tiempo surge la duda a propósito de si la cátedra de gimnasia, desde su implementa- 
ción en 1876, se impartió ininterrumpidamente a partir de esta fecha y en lo que resta del siglo xIX.

¿Por qué surge esta duda? Por los recibos de pago del año de 1876 sabemos que Noreña impartió clases de gimnasia de enero a julio. ${ }^{6}$ Después de julio de 1876 la huella de Noreña, como profesor que imparte la clase de gimnasia, se vuelve borrosa, así como la huella misma de esta cátedra en el plantel. En los señalamientos de exámenes, actas de distinta índole, calificaciones, programas y listas de materias, entre varios documentos consultados, de los años 1877 a 1888, no vuelve a aparecer enlistada o mencionada esta asignatura. Es decir, no hay algún indicio contundente de la práctica de ejercicios gimnásticos en el Colegio después de 1877 y hasta aproximadamente 1888.

No es sino hasta el año de 1889 que volvemos a encontrar indicios de la praxis gimnástica en los documentos. ${ }^{7}$ ¿Por qué ese silencio a lo largo de estos años? Son plausibles varias hipótesis. De entrada sería factible que la gimnasia en estos años no fuera considerada como una rama sujeta a examen o a calificación en el Colegio -a pesar de que en algunas escuelas públicas y privadas de la ciudad se realizaran exámenes públicos de gimnasia (Garrido, 2016, p. 62)-y que por eso no aparezca registrada en ninguna acta de examen o de calificaciones. La ausencia de calificaciones y su registro en el programa de exámenes o como materia a lo largo de estos años, sin duda no implica que se anulara su ejercicio. Otra opción es que su implementación quedara englobada como parte de otra materia, particularmente la de "higiene" (cátedra instaurada en 1878), y que por eso no aparezca alusión clara en los documentos en general. En este caso, como se verá más adelante, quizá sea la maestra titular de grado o de cátedra (o la suplente), la encargada de impartir y dirigir los ejercicios gimnásticos: lo que explicaría la falta de referencias claras a la figura del "profesor de gimnasia" y a la materia misma. Otra posibilidad más simple es que su práctica se espaciase, se dejase a un lado o se abandonara, al dejar Noreña de dar clases en el establecimiento y que esta no se retomara hasta encontrar nuevamente un profesor de gimnasia adecuado.

A partir de 1890, el general Feliciano Chavarría ocupará el puesto de profesor de gimnasia y la cátedra, tanto en el departamento de internas como

${ }^{6}$ Comprobantes de pago. Útiles escolares. 1875-1878. Estante 17, tabla IV, vol. 2, doc. núm. 20. АнјMBN, México.

${ }^{7}$ Libro copiador. 1886 a 1890. Estante 6, tabla v, vol. 15, fs. 302-312, fls. 18719 a 18729. АHJMBN, México. 
en el de externas, quedará a su cargo. ${ }^{8}$ Si bien a Chavarría lo sustituirán posteriormente otros profesores y la clase en general sufrirá ciertas modificaciones de horario y duración (y no siempre se impartirá a todos los grados escolares), es posible afirmar que es a partir de la última década del siglo xix que la práctica de ejercicios gimnásticos -por lo menos oficialmente- permanece como una constante del acontecer cotidiano de la vida de las educandas en el colegio hasta 1915, año en el que la cátedra se suprime por falta de personal y recursos, debido a la agitada e inestable situación que se vivía en el país y que afectó fuertemente al Colegio este último año en particular. ${ }^{9}$

¿Por qué es importante observar el desarrollo temporal de la cátedra? El caso de Vizcaínas permite apreciar en primer lugar que, a pesar de las justificaciones teórico-corporales sobre la importancia de la gimnasia para la educación de los cuerpos, la implementación efectiva de este discurso no tuvo siempre un desarrollo continuo o uniforme en los planteles educativos del país (como Vizcaínas) y enfrentó dificultades que sólo podemos inferir. Estas dificultades pudieron estar vinculadas con la figura y el puesto del profesor de gimnasia y la formación misma de quien desempeñaba esta cátedra. O bien, con temores, resistencias y menosprecio del mismo personal del Colegio y las educandas en general. ${ }^{10}$ Traigo a colación nuevamente el estudio de Garrido (2016) para abonar a esto último. Garrido argumenta que a pesar de las opiniones favorables vertidas en la prensa mexicana y en los tratados en torno a la educación gimnástica del periodo, además de los esfuerzos de las autoridades escolares y los médicos en esta materia, todavía para 1876 la población general en México mostraba resistencia o temor hacia la práctica de ejercicios gimnásticos por considerarlo inútil o peligroso. Pensamos que lo anterior se acentuaba aún más en el caso de niñas y mujeres por la fragilidad de sus cuerpos.

Incluso si el silencio o la ausencia contundente de alusiones o indicios del ejercicio gimnástico en la documentación no implicó que esta se abandonara o se anulara, lo anterior sigue dando cuenta de la importancia y sistematización de la misma, en términos de exámenes, calificaciones y como parte de otras materias. Es decir, si mantenemos la hipótesis de que la práctica de ejercicios gimnásticos se mantuvo ininterrumpida en el plantel desde su instauración, la

8 Informes y documentos anexos. Estante I, t. III, vol. 15. AHJMBN, México.

9 De igual forma, entre 1915 y 1921 esta cátedra comenzará a mutar y transformarse en la clase de "cultura física", "ejercicios físicos" y "educación física”. Lo anterior es tema de otro ensayo.

10 En otro espacio desarrollo la posible "recepción" o "agencia" que las alumnas y profesoras hicieron de la gimnasia. 
ausencia de calificaciones y exámenes permite pensar que, en un primer momento -médicos, profesores y autoridades del Colegio- quizá sólo buscaron fomentar ejercicios corporales entre las educandas, sin evaluarlos o sistematizarlos. Ese fue el caso más adelante, a partir de 1889, en que encontramos calificaciones mensuales y vemos que la gimnasia formó parte de los ramos que se evaluaban en los exámenes anuales, lo que implicó hasta cierto punto que se estableciera paulatinamente un sistema de lectura y de evaluación del cuerpo de las colegialas y sus movimientos, mismo que posibilitó asignar calificaciones.

En segundo lugar, es importante relacionar esta cátedra con el desarrollo de la higiene en México y particularmente con el Congreso Higiénico Pedagógico de 1882 y los subsecuentes congresos nacionales de Instrucción Pública de 1890 y 1891. Estos congresos, al reestructurar las políticas educativas en materia de planes de estudio y formas de enseñanza, reforzaron la necesidad del ejercicio físico (y su evaluación) en el ámbito escolar, en aras de contribuir a la buena salud y el perfeccionamiento corporal de los educandos. Además, para algunos investigadores, estos congresos simbolizan la injerencia del campo médico en la escuela y el hogar, al establecerse como nuevos referentes que censuran y norman comportamientos individuales y colectivos (Carrillo, 1999; Chaoul, 2012). Lo formulado en este congreso, así como las subsecuentes legislaciones en esta materia, sin duda impactaron el desarrollo de la gimnasia al interior de la escuela. Y nos revelan, como lo ha señalado Agostoni (2002), la importancia que para los médicos higienistas tuvo la educación de la población y la creación de hábitos higiénicos entre los mexicanos. Hábitos que -en el último decenio del siglo xIx y por lo menos en El Colegio de la Paz- se validaron a través de los exámenes.

\section{LOS PROFESORES Y LOS MÉTODOS DE GIMNASIA}

El programa o método gimnástico fue uno de los elementos que adquirió especial importancia en el desarrollo y consolidación de la gimnasia decimonónica. La importancia del método o programa recaía en que a través de este se sistematizaba el ejercicio corporal y se posibilitaba obtener los resultados deseados. Entre todas las ramas y métodos gimnásticos desarrollados a lo largo del siglo xix, fue la llamada gimnasia higiénica la rama que más se popularizó y la que se implementó en los planteles escolares, en vista de que era la que buscaba grosso modo preservar la salud de la población y robustecer 
los cuerpos. La gimnasia higiénica, además, era la que tenía más influencia benéfica sobre los cuerpos y los "organismos sanos" y la que podía aplicarse y adaptarse a todos los sexos y edades (Campo, 1878 p. 13). Conviene notar que, en este contexto, la gimnasia se entendió desde un punto de vista muy general. De ahí que en el tránsito del siglo XIX al Xx se englobara como ejercicio gimnástico a diversos tipos de actividades que hoy en día no tendrían mucha relación entre sí, como las tablas calisténicas, la natación y el coro, entre otros (Chávez, 2007, p. 5).

En el proyecto inicial de Castilla encontramos alusión a la "autogimnasia" como método a privilegiar en el Colegio. Documentos posteriores, por otro lado, distinguen que la gimnasia que debe practicarse en Vizcaínas es la "gimnasia de salón”. Pero ¿qué era y por qué se consideraba adecuada para la educación de las colegialas? Chávez (2006) argumenta que a finales del siglo XIX, en México, se difundió una técnica de enseñanza gimnástica adaptada a los espacios reducidos: la "gimnasia de salón". El mote quizá obedece al hecho de que uno de los primeros textos de gimnasia que se difundió en el país fue el del francés Eugenio Paz: Pequeño curso de gimnasia de salón sin aparatos, publicado en 1880. Chávez (2006) apunta que el "manual de Paz se distinguió por apartarse de los supuestos militarizados con los que la mayoría de las veces se asoció a la ejercitación física y porque sus argumentos apelaban al conocimiento científico del cuerpo humano" (p. 118).

Una lectura atenta revela que ambas palabras en los textos y en la cotidianidad en realidad se utilizaron para aludir a métodos y técnicas muy semejantes, si no es que idénticas que se adaptaron a las escuelas mexicanas y a las diferencias entre los sexos y las edades. En última instancia, estos métodos referidos y privilegiados en los documentos que encontramos en Vizcaínas hacen alusión, por un lado, al interés de las autoridades del Colegio y de los profesores en adaptar los métodos gimnásticos a los cuerpos de las colegialas y las premisas higiénicas de la época. Y, por otro, al interés de que las alumnas practiquen una gimnasia que beneficie su desarrollo corporal y se adecue al mismo.

En Vizcaínas, como parte de esta "gimnasia de salón", las colegialas practicaron distintos tipos de ejercicios dependiendo de su edad. La justificación detrás de esta diferenciación se encontró, sin duda, en sintonía con las ideas médicas e higiénicas de la época y con las características fisiológicas que se pensaba gobernaban a los cuerpos. Los argumentos que justificaban esta diferenciación tienen que ver con la idea de que el ejercicio y el movimiento del cuerpo debían ser correlativos al desarrollo de los órganos de los indi- 
viduos según su edad y su sexo. Así, los distintos movimientos propuestos para ser ejecutados con orden y disciplina en la clase de gimnasia incidían en ese sentido en el desarrollo deseable del cuerpo de niñas y jóvenes. De ahí que los ejercicios no debían ser los mismos (principalmente en intensidad y repeticiones) para cuerpos pueriles o para cuerpos que entraban en el pleno desarrollo sexual. La edad y el sexo constituyeron un factor de suma importancia en la lectura gimnástica moderna, pues constituyen signos "visibles" y "científicos" que gobernaron las representaciones del cuerpo (Castillo, 2006).

En el caso del Colegio esta premisa de graduar los ejercicios y los movimientos del cuerpo según las etapas no fue ajena. Un ejemplo de ello son los programas de enseñanza de clases de 1895, diseñados por las profesoras. En estos se aprecian dos elementos importantes: a) que los ejercicios no son los mismos en la secciones de párvulos (donde se practican "juegos libres" y "juegos gimnásticos") y en las de grados más avanzados; $b$ ) y que se agregan e introducen, conforme se crece, distintos tipos de ejercicios que aumentaban la complejidad y frecuencia. ${ }^{11}$ Así, en sintonía con los tratados de gimnasia y conforme se desarrollaba el cuerpo de las alumnas, a lo largo de su trayectoria escolar durante esta clase y de modo gradual se practicaron: saltos, ejercicios de respiración y de equilibrio, flexiones de brazos y piernas (con o sin bastón), saltos, marchas (con o sin bastón) y movimientos oscilatorios de brazos sosteniendo pesas ligeras (mazas), entre otros. En última instancia, el ejercicio adecuado fue aquel que privilegió vía series y repeticiones -tres veces por semana en un lapso de 20 a 30 minutos- los "movimientos naturales" del cuerpo femenino en aras de vigorizar su constitución, pero sin dañar sus órganos y sus formas.

Lo anterior no resulta trivial, el ejercicio corporal encarnado en el movimiento de los distintos órganos y partes del cuerpo era, por más evidente que parezca, el agente principal que empleaba cualquier método gimnástico. Recordemos que "ejercicio" significaba en este contexto "el movimiento o la acción repetida de los órganos del cuerpo" (Campo, 1878, p. 13). Uno de los fines del ejercicio corporal fue el de fomentar el movimiento general y "natural" del organismo (un movimiento que tenía que ser regular, continuo, rítmico, vigoroso o moderado): era este movimiento del organismo (principalmente sanguíneo y muscular) el que estaba en el origen de los múltiples

${ }^{11}$ Documentos presentados a la Junta de 1895. Estante 19, tabla I, vol. 7, fls. NC2233 a NC2252. АнJMBN, México. 
beneficios del ejercicio físico (Sánchez, 1883, p. 13). Además, la importancia del movimiento muscular radicaba en que era considerado uno de los principales medios capaz de corregir la morfología humana (Vigarello, 2005, p. 17). La insistencia en distinguir, describir y sistematizar los "movimientos del cuerpo" no es algo menor en este contexto: constituye una de las bases de todos los esquemas gimnásticos que surgen a finales del siglo XVIII. En suma, será la ejecución del movimiento la base de la "lectura" que el profesor de gimnasia hace sobre el cuerpo del ejercitante. Además, es el movimiento el que posibilita y permite construir calificaciones de la clase y los exámenes de gimnasia. Y revela una concepción nueva del cuerpo humano que implica, entre muchas cosas, la posibilidad de medirlo y compararlo, e incluso experimentarlo (Vigarello y Holt, 2005, pp. 304-305).

Igualmente, el papel y formación del profesor fue otro elemento clave y esencial en la práctica gimnástica moderna. Esta figura -idealmente formada en conocimientos fisiológicos, anatómicos y de método gimnástico-era la encargada (en ocasiones junto a un médico) de elaborar un diagnóstico del "ejercitante", en aras de prescribir y ajustar el tipo de ejercicio a realizar, la parte del cuerpo a trabajar y la frecuencia del ejercicio según el temperamento, el sexo, el estado intelectual, la robustez corporal y el objetivo del mismo, entre otros factores. Este era esencial para marcar el ritmo a través de un instrumento musical, el grito de consignas, o por medio de cantos y coros. El ritmo era un elemento necesario, particularmente en la gimnasia grupal (como la que se practicaba en el plantel), ya que garantizaba el compás, la regularidad y el orden de todos los movimientos corporales. Es importante subrayar que sólo mediante la disciplina, el orden y la regularidad, el ejercicio corporal podía incidir verdaderamente en el desarrollo físico, intelectual y moral de cada individuo. Los profesores de gimnasia debían ser receptivos al papel que jugaba el ritmo y la música en el desarrollo de sentimientos heroicos y nobles. De ahí que idealmente estos fuesen, hasta cierto punto, una especie de directores de orquesta con los que se aseguraba el diagnóstico correcto del ejercitante, la implementación adecuada de ejercicios y la garantía de la disciplina y ritmo. Lo anterior no es asunto menor, una gimnasia mal dirigida podía tener efectos funestos en el organismo. La práctica de ejercicios corporales exenta de las consideraciones necesarias podía "producir trastornos de importancia, como son los del sistema nervioso y sentidos, y ocasionar demacración, vejez prematura, reumatismo, etc." (Elizalde, 1867, p. 11). 
La junta directiva del Colegio fue sensible, en ese sentido, al papel que tenía el profesor de gimnasia. La junta era la encargada de designar y ratificar a los profesores de esta materia. En este periodo se turnarían en el puesto tanto hombres como mujeres, aunque el papel de estas últimas, a diferencia del masculino, iría paulatinamente legitimándose. Como he mencionado, Noreña fue designado como el primer profesor de gimnasia de Vizcaínas. ${ }^{12} \mathrm{~A}$ pesar de su corto paso por la cátedra, su influencia fue significativa, en primer lugar, porque a lo largo de los años siguió siendo una figura de referencia gimnástica en el establecimiento, puesto que su nombre aparece enlistado como sinodal del examen de gimnasia en distintos años y para distintas secciones. ${ }^{13} \mathrm{Y}$, en segundo lugar, porque colegas y alumnas suyas -interesados en la promoción de la gimnasia en las escuelas- figurarán como profesores de la cátedra en el Colegio en los años siguientes.

Uno de esos colegas fue Feliciano Chavarría (i?-1894), ${ }^{14}$ quien fue designado como profesor de la cátedra en 1890 . El desempeño de Chavarría al frente de la cátedra fue más prolongado (ocupó el puesto por lo menos hasta finales de 1892), aunque más accidentado debido a sus constantes ausencias por negocios y enfermedades. ${ }^{15}$ Otra figura masculina titular, que tuvo un papel intermitente y significativo de 1893 a 1897, fue la del asturiano José Sánchez Somoano (1850-1913). ${ }^{16} \mathrm{El}$ papel de Sánchez es importante para pensar las transformaciones de la práctica gimnástica en el país, ya que este profesor fue un activo promotor de la enseñanza gimnástica en las escuelas primarias y se interesó en formar profesoras de gimnasia (Torrabadella-Flix, 2018, pp. 549-596). Sánchez es el profesor que aparece en las fotografías de la clase de gimnasia que se guardan en el archivo histórico del Colegio, tomadas alrededor de $1896 .{ }^{17}$

${ }_{12}$ Para más información sobre la formación de Noreña, consúltese Garrido (2016, pp. 4856 y $110-111)$.

${ }_{13}$ Documentos presentados a la Junta de 1891. Estante 19, tabla I, vol. 2, fl. NC508; Actas de exámenes del año 1892. Estante 4, tabla IV, vol. 9, f. 56, fl. NC13992; Calificaciones de 1893. Estante I, tabla Iv, vol. 3, fls. NC14613B, NC14661B, NC14616B y NC14573B. АнJMBN, México.

${ }^{14}$ Para más información sobre la formación de Chavarría, consúltese Garrido (2016, pp. $46-48$ y 71$)$.

${ }^{15}$ Libro copiador. 1886 a 1890. Estante 6, tabla v, vol. 15, f. 471, fl. 18888; Documentos varios. Mantenimiento. Planes de estudio. Reglamento. 1888 a 1893. Estante 19, tabla IV, vol. 14; Documentos presentados a la Junta de 1890. Estante 19, tabla I, vol. I. AHJMBN, México.

${ }^{16}$ Aparece también como José Sánchez y González de Somoano.

${ }^{17}$ Fotografía de la clase de gimnasia de profesoras (ca. 1896). Sección fotografía antigua, paquete 2, sobre 4. AHJMBN, México. 
También aparece marcando el ritmo a las colegialas de Vizcaínas en la "vista" que filmó en 1896 el técnico francés Gabriel Veyré en su paso por México. ${ }^{18}$

\section{LAS PROFESORAS Y EL APRENDIZAJE GIMNÁSTICO}

Una cuestión significativa es que, ante la falta o la ausencia de la figura del profesor de gimnasia, fueron las profesoras -alumnas normalistas del Colegio en su mayoría- las que se desempeñaron al frente de esta cátedra. Encontramos que en ciertos momentos del periodo aquí estudiado las profesoras de los distintos grados de primaria tuvieron la obligación de dar la clase de gimnasia; o bien, turnarse en su impartición cuando no había profesor. ${ }^{19}$ En ciertos años encontramos la alusión directa a que una determinada profesora en particular posea la exclusividad para la impartición de la clase. Las profesoras que aparecen regularmente mencionadas se enlistan en el cuadro 2.

Chávez (2006) señala que todavía a finales del siglo xix la formación de profesores especializados en gimnasia estaba poco institucionalizada en el país. Generalmente aquellos gimnastas "experimentados" se habían formado en la milicia o en gimnasios particulares (como es el caso de Noreña, Chavarría y Sánchez). En este periodo iniciaban apenas los esfuerzos por uniformar la práctica gimnástica en México, mediante inspecciones y la obligatoriedad de ciertos manuales escolares. Lo anterior nos permite pensar en la formación que debieron de haber tenido los profesores que ejercieron en el Colegio y dar una respuesta parcial a la pregunta sobre la educación y acreditación de los mismos. Varias preguntas se imponen para el caso de las profesoras: ¿cómo legitimaban su "lectura" del cuerpo y su competencia en la materia?, ¿cómo obtenían sus conocimientos de gimnasia: leyendo, observando o preparando un examen?, ¿por qué estas señoritas se pensaron como idóneas para impartir

${ }^{18}$ Veyré fue el encargado de traer consigo a América el cinematógrafo Lumière. Durante su estancia en México realizó diversas filmaciones. Una de estas es la de las "Alumnas del Colegio de la Paz en traje de gimnastas". La filmación puede consultarse en https://catalogue-lumiere.com/defile-de-jeunes-filles-au-lycee/

${ }^{19}$ Cursos y comunicaciones presentadas a la H. Junta Directiva. 1885, 1888, 1895. Estante I, tabla III, vol. 14, varias fojas; Actas de juntas celebradas de febrero de 1893 a julio de 1901. Estante 4, tabla v, vol. 14, f. 62 verso y folio 18892 verso; Documentos presentados a la junta de 1896. Estante 19, tabla I, vol. 8, fl. NC2679. AHJMBN, México. 


\section{Cuadro 2. Suplentes-adjuntas y profesoras de gimnasia}

Lista de profesoras $y$

alumnas normalistas

Cargo y años en el que ejerce

Procedencia institucional

Leonor Marenco

Amalia Díaz
Fernández
María Figueroa de
Lobato

Suplente-adjunta en 1890, 1896 y 1897

Suplente-adjunta en 1892, 1893 Alumna del Colegio de la Paz y 1894

Profesora interina de 1897 a 1899

Adela Mörner

Suplente-adjunta en 1894 y 1899

Profesora titular de 1901 a 1905

Cira Lejarza
Guadalupe
Márquez
Luz García
Sánchez

Suplente-adjunta en 1903

Suplente-adjunta en 1903

Profesora entre 1905 y 1908

Feliciana Guzmán

Esther Pérez

Profesora en 1908

Palacios

Soledad Herrera

Profesora de 1908 a 1909

Ignacia Burgos

Refugio Salgado

Concepción

Unánue
Profesora de 1909 a 1914

Profesora en 1915

Profesora de la cátedra de párvulos (en la que impartía gimnasia obligatoriamente)

Profesora de la cátedra de párvulos
"Maestra de ejercicios físicos" en la Escuela Normal para Profesoras

Alumna del Colegio de la Paz Alumna del Colegio de la Paz Alumna del Colegio de la Paz

"Profesora de gimnasia" en la Escuela Normal para Profesoras Alumna del Colegio de la Paz Alumna del Colegio de la Paz Alumna del Colegio de la Paz Alumna del Colegio de la Paz Alumna del Colegio de la Paz Fuente: АнјмвN, México. 
la cátedra (como profesoras o adjuntas)?, ¿su selección obedece al azar o a auténticas competencias "gimnásticas"?

Las preguntas anteriores son pertinentes en tanto que la cátedra de gimnasia se concibió, por lo menos teóricamente, para ser impartida por un profesor con conocimientos particulares en el tema (conocimientos que entraban en consonancia con una lectura particular del funcionamiento y movimiento del cuerpo). ${ }^{20}$ Conviene nuevamente recordar que en este contexto fueron los movimientos "razonados" y "disciplinados" del cuerpo dirigidos por el profesor o profesora los que garantizaban los beneficios higiénicos, fisiológicos y estéticos del ejercicio corporal en el espacio escolar. Además, era este movimiento razonado y disciplinado el único capaz de replegar sus efectos al interior del cuerpo humano y de incidir en el intelecto, la voluntad y la moral de los educandos. Lo anterior constituía una de las bases de lo que aquí llamaremos como "lectura gimnástica" del cuerpo humano. En el caso de las profesoras, las preguntas anteriores no son del todo fáciles de responder. Empero es viable obtener ciertos indicios y aventurar algunas hipótesis. A partir de la década de 1890 encontramos documentos que atestiguan una mayor sensibilidad por parte de las autoridades del Colegio (principalmente de la junta de profesores en voz de Luis E. Ruiz) respecto de que las profesoras designadas como suplentes de las cátedras sean "competentes" en las materias que suplen. ${ }^{21}$

Por ejemplo, en junio de 1892, la junta de profesores -instada por Ruizsugiere a la junta directiva que se fije el nombramiento de suplentes fijas para cada materia que se imparte, en razón de que no todas tienen "iguales aptitudes para todos los ramos de enseñanza, [y] no se encuentran en condiciones igualmente favorables para el cumplimiento de [impartir las] clases". ${ }^{22}$ Los adjetivos y criterios: "capaz", "apta”, "competente" y "tener alguna práctica” comienzan, a partir de esta década, a aparecer en los documentos que nos hablan de la elección de las suplentes fijas y profesoras de gimnasia. ${ }^{23} \mathrm{~A}$ pesar de su poca precisión, estos adjetivos nos permiten pensar los criterios bajo los

20 Documentos varios. Mantenimiento, Planes de estudio, Reglamento. 1888-1893. Estante 19, tabla IV, vol. 14, núm. 2 bis. AнјмBN, México.

${ }^{21}$ Documentos presentados a la junta de 1890. Estante 19, tabla I, vol. 1, fl. NC 287. AHJMBN, México.

${ }^{22}$ Documentos presentados a la Junta de enero a agosto de 1892. Estante 19, tabla I, vol. 4, fl. NC1160. Анјмвn, México.

${ }^{23}$ Copias de comunicaciones 1893 a 1894. Estante 4, tabla III, vol. 30, comunicación núm. 10; Documentos presentados a la Junta de enero a agosto de 1892. Estante 19, tabla I, vol. 4, fls. NC1155 y NC1217. АнјмвN, México. 
cuales fueron designadas las profesoras y abren las siguientes preguntas: ¿qué implicaba ser "competente" y "apta" en el marco de la enseñanza gimnástica?, ¿estaban estos adjetivos vinculados al desempeño de movimientos corporales y a la lectura gimnástica del cuerpo? o ¿entraban en juego otras "aptitudes" como la puntualidad, la moralidad y el decoro personal?

En esta temporalidad podemos calificar el "aprendizaje" gimnástico-corporal de las profesoras (y también hacerlo extensible a las alumnas) como empírico y teórico. Es decir, un aprendizaje "empírico" obtenido a partir de la posible asistencia a la cátedra de gimnasia y la implementación de exámenes (como sustentantes o sinodales). Y un aprendizaje teórico obtenido a partir de la lectura de ciertos textos higiénicos y gimnásticos ubicados en la biblioteca del Colegio y de materias que proporcionaron un conocimiento del funcionamiento del cuerpo y de la importancia del ejercicio como medida higiénica. Este conocimiento se difundió principalmente a través de la clase de higiene establecida en el Colegio a partir de 1878. Desde esta perspectiva, el desarrollo corporal sólo era plausible por medio de la higiene: único arte apto para la "conservación fisiológica" de las facultades físicas de los niños (Memorias del primer Congreso Higiénico-Pedagógico, 1883). Importa subrayar que es, sobre todo aquí, en este diseño curricular y en el interés por la formación de las profesoras, donde podemos ver reflejada esta idea del Colegio como un escaparate de la modernidad porfiriana y de la importancia que ciertos médicos, higienistas y gimnastas otorgaron a la educación de la mujer.

Ahondo primero en torno al aprendizaje que califico como "empírico", centrándome especialmente en las profesoras. Es importante subrayar (por más evidente que esto pueda parecer) que la asistencia a la clase de gimnasia implicó (además del trabajo personal sobre el cuerpo) el aprendizaje de movimientos corporales y ejercicios musculares entre las profesoras-alumnas, que posteriormente podía ser reproducido por ellas. Es sugerente que algunas de las profesoras antes mencionadas (véase cuadro 2) fueron también simultáneamente, durante el tiempo que enseñaron, alumnas de la cátedra de gimnasia. Un ejemplo de esto es la clase de gimnasia, con carácter obligatorio, exclusiva para profesoras que se establece en marzo de 1893 a cargo de Sánchez. ${ }^{24}$ Esta se impartía los martes, jueves y sábados de 5 a 6 de la tarde. Entre

${ }^{24}$ Documentos presentados a la Junta de enero a agosto de 1893. Estante 19, tabla I, vol. 4, fls. NC1443, NC1456, NC1463, NC1480, NC1508, NC1526, NC1536, NC1554, NC1569, NC1622, NC1623 y NC1672. AHJMBN, México. 
otras cosas las profesoras, bajo la supervisión del profesor, hacían "ejercicios de mazas". ${ }^{25}$ Lo anterior es signo del interés de la junta directiva para que las profesoras, al igual que el resto de las alumnas, practicaran periódica y metódicamente la gimnasia. Importa subrayar lo anterior debido a que implicó la posibilidad de obtener una formación particular o complementaria en este ramo, misma que posteriormente podría ser replicada o implementada por las profesoras al suplir o asumir la titularidad de la enseñanza gimnástica.

Conviene señalar que no se conserva mayor documentación que dé cuenta del tiempo que permaneció vigente la cátedra de gimnasia exclusiva para las profesoras con carácter obligatorio. Un relato reproducido en las memorias de Julia Mörner (2001, pp. 133-134), antigua alumna y profesora del Colegio, hace pensar que quizá la clase anterior se trató de un evento particular en la vida del plantel, destinado a que las profesoras adquirieran un diploma de gimnasia. Incluso si esta clase funcionó sólo ese año (1893) o se concibió hipotéticamente para que las profesoras pudieran acreditar el examen de gimnasia o mejorar sus conocimientos en la materia, lo que importa notar es que estos indicios nos permiten pensar los caminos que siguió la formación corporal posible y deseable de las señoritas en materia de gimnasia en el Colegio.

De lo anterior se desprende además la relevancia que tuvieron los exámenes anuales en el aprendizaje empírico-corporal de las profesoras. Es decir, los exámenes aparecen también como otro instrumento de aprendizaje corporal que contribuyó en mayor o menor grado a legitimar una "lectura del cuerpo" y obtener competencia en la materia. Las profesoras del Colegio (así como las educandas) fueron examinadas en este ramo en más de una ocasión. ${ }^{26}$ Así, observamos que conforme se termina el siglo, los exámenes de gimnasia servirán para acreditar y legitimar una lectura e instrumentalización del cuerpo, al ser la gimnasia una de las competencias a evaluar que se comienza paulatinamente a integrar en la formación escolar y como normalista. ${ }^{27}$ De ahí

${ }^{25}$ Copias de comunicaciones de 1893 a 1894. Estante 4, tabla III, vol. 30, comunicación núms. 8 y 10; Actas de juntas celebradas de febrero de 1893 a julio de 1901. Estante 4, tabla v, vol. 14, fs. 8 a 12 , fls. $18838-18842$. АнјмBN, México.

${ }^{26}$ Calificaciones. 1893. Estante I, tabla IV, vol. 3, fl. 14605B; Lista de calificaciones de las alumnas de primaria elemental, superior y normal, 1890 y 1897 . Estante I, tabla I, vol. 1bis, s. f., AHJMBN, México.

${ }^{27}$ Actas de juntas celebradas de febrero de 1893 a julio de 1901. Estante 4, tabla v, vol. 14. AHJMBN, México. 
que -en lo particular- los exámenes sean importantes, ya que son muestra de un conocimiento que, por creerse relevante para la formación docente de las mujeres, se irá sistematizando en aras de otorgar competencia a las profesoras en el ramo. Sin duda, esta cuestión debe vincularse a los estudios sobre la profesionalización de la carrera normal para las mujeres y la institucionalización de la enseñanza de educación física en el país en este periodo (Alvarado, 2004). Este proceso de institucionalización tuvo como fin difundir y uniformar la enseñanza gimnástica a través de la implementación de exámenes, la creación de academias de gimnasia e inspecciones, así como la publicación de una metodología particular vía los manuales escolares (Martínez, 2011).

Un aspecto importante de este proceso y que echa luz a la interrogante sobre la formación gimnástica de las profesoras del Colegio, fue la creación de la Academia de Gimnasia Sueca, fundada por Alberto D. Landa (la cual funcionó de 1903 a 1905 al interior de la Escuela Preparatoria) (Chávez, 2006, pp. 83-85). Sabemos que las profesoras del Colegio -Luz García Sánchez, Adela Mörner y Amalia Díaz- fueron acreditadas en esta academia, entre 1902 y 1904. Para ello debieron pasar una serie de pruebas académicas que constataron la adquisición de los conocimientos contemplados en el programa. Aquí, las clases y el conocimiento se dividía en práctico y teórico. En las clases prácticas se realizaban diferentes lecciones de tipos de ejercicios, mientras que en las teóricas se ahondaba en conocimientos anatómicos y fisiológicos que buscaban mostrar la influencia del ejercicio físico sobre el cuerpo humano. ${ }^{28}$ Estas profesoras, principalmente Mörner y Díaz, contaron con el apoyo pleno de la junta directiva del Colegio para complementar su formación como profesoras de gimnasia. Otro signo que nos muestra la importancia que adquirió la educación de la mujer como una de las bases del progreso y el fomento de la salud pública y privada.

En cuanto al aprendizaje "teórico", destaca la importancia que tuvo la cátedra de higiene como medio para proporcionar a las alumnas de escolaridad avanzada un conocimiento del funcionamiento del cuerpo y de la importancia del ejercicio como medida higiénica. En este periodo los médicos no dejaron de señalar que de nada servían las disposiciones legislativas y las acciones del gobierno "frente a la falta de una educación moral, intelectual e higiénica de los mexicanos" (Agostoni, 2002, p. 5). De ahí que la práctica de

${ }^{28}$ Informe rendido por el C. profesor Alberto D. Landa de la Academia Gratuita de Gimnasia Sueca por él dirigida. Estante 22, tomo II, vol. 7, pp. 799-800. АHJMBN, México. 
la gimnasia en este periodo no puede entenderse sin la educación higiénica, de la que proviene hasta cierto punto. La higiene se entiende en este contexto como "el arte de conservar la salud, es decir, el conjunto de reglas cuya observancia nos hace permanecer sanos" (Ruiz, 1888, p. 5). No hay que olvidar que la gimnasia es en gran medida promovida socialmente con ese fin y objetivo. Además, es gracias al llamado "impulso higiénico" -como han señalado varias investigaciones- que se comenzó a difundir la gimnasia en las escuelas, particularmente entre la población escolar femenina.

En este contexto, el papel de los médicos e "higienistas" fue fundamental, pues fueron estos los que "adaptaron" los ejercicios a las características anatómicas del cuerpo femenino y sus funciones fisiológicas (Chávez, 2006, pp. 81-82). Pero no sólo eso, según constatamos para el caso del Colegio, son también estos médicos higienistas (Martínez del Villar, Ruiz y Liceaga) los que difunden, socializan y adaptan entre las alumnas -a través de sus clases, exámenes y textos-ciertos conocimientos fisiológicos y anatómicos del cuerpo humano. Conocimientos que sirvieron como marco para orientar no sólo las prácticas gimnásticas sino también las prácticas corporales en un sentido más general y, por qué no, una cierta representación del funcionamiento del cuerpo entre las colegialas.

Los programas de clase y documentos que nos hablan de los contenidos que revisaban y que tenían que aprender las alumnas para sustentar y aprobar los exámenes correspondientes a esta materia son valiosos registros que nos muestran el conocimiento higiénico y "científico" que se difundía sobre el cuerpo humano. Uno de los temas abordados en esta clase era precisamente el de "ejercicios musculares y movimientos". Este tema -que tenía como fin mostrar la notable influencia de esta actividad en la salud- englobaba, en palabras de Martínez, "diversas especies de ejercicios, [la] necesidad del ejercicio corporal para la salud, [y distintos tipos de] ejercicios gimnásticos muy especialmente para el desarrollo de la caja torácica." ${ }^{29}$

Aunado a estos documentos manuscritos, los libros que se utilizaban en clase constituyen otra valiosa pista para ver el tipo de conocimiento corporal que era socializado en el plantel. Además de estar ubicados en la biblioteca colegial del siglo XIX, sabemos por las actas de las juntas de profesores que

${ }^{29}$ Documentos presentados a la Junta de 1895. Estante 19, tabla I, vol. 7, fl. NC2286. AHJMBN, México. 
estos textos se leían en clase y constituían la base de los contenidos del curso. ${ }^{30}$ De entre estos textos nuevamente destacan aquellas obras de la autoría de los profesores antes mencionados. Como: Nociones elementales de higiene privada (1888), de Luis E. Ruiz, y Tratado de higiene privada y social por Lacassange (1881), de I. Martínez del Villar. Fue particularmente este último texto el que más se usó para esta clase. En este, Martínez hizo énfasis en la idea de que las principales condiciones para una buena salud eran el aire oxigenado, la alimentación suficiente y el ejercicio muscular. A propósito de esto último, Martínez anotaba que debido a que la masa muscular formaba la mayor parte del volumen de nuestro cuerpo, el ejercicio se volvía indispensable para "la actividad de las combustiones", de la nutrición y para la manutención del calor animal, en última instancia: para el sostenimiento mismo de la vida (Martínez del Villar, 1881, pp. 120-123).

Sin los conocimientos que proporcionaron estas otras educaciones teórico-corporales, el papel de la gimnasia al interior del Colegio no puede entenderse. Bajo ese tenor pueden leerse las reglas proporcionadas por Liceaga a las colegialas, las cuales se difundieron al interior del Colegio a modo de manuscrito. ${ }^{31}$ Para conservar la salud y correcto vigor corporal, Liceaga recomendaba seguir ciertas reglas higiénicas. Estas reglas aludían a distintos aspectos (todos tópicos comunes de los textos de higiene decimonónica), como la vestimenta, el baño, las habitaciones y la ejercitación física. Con respecto a la ejercitación señalaba: "los ejercicios deben practicarse todos los días a fin de que se conviertan en hábitos para que se continúen haciendo la vida entera" (p. 10). Liceaga destacaba que para que las alumnas se dieran cuenta de la importancia de dichas reglas, era necesario transmitirles ligeramente "una idea del sistema y aparatos que componen el cuerpo humano y de su manera de funcionar", en aras de que, por un lado, comprendan y no olviden esas nociones elementales, $y$ por otro, para que puedan explicarlas a los niños (p. 41). Se puede afirmar hasta cierto punto que, para volverse hábito, el ejercicio corporal requirió de una base científica, teórica e higiénica accesible

30 Señalamientos de exámenes. 1881. Estante 4, tabla III, vols. 26 y 27, f. 22, fl. 10206; Junta de profesores. 1892-1906. Estante 4, tabla III, vol. 28, acta núm. 6, fs. 5 a 7, fls. 10324 a 10326; Documentos presentados a la Junta de 1895. Estante 19, tabla I, vol. 7, fls. NC2256 a NC2258; Documentos varios. Mantenimiento, Planes de estudio, Reglamento. 1888-1893. Estante 19, tabla IV, vol. 14. АнJMBN, México.

${ }^{31}$ Cinco libretas manuscritas de alumnas, reglas de higiene del doctor Liceaga [manuscrito]. Estante 22, tabla III, vol. 5, pp. 1-45. АнJMBN, México. 
a todos (en este caso accesible a las alumnas), es decir, una base científica-teórica que sirvió de sustento a las reglas de higiene y como marco al ejercicio del cuerpo. Insisto, fuera de este sustento, el ejercicio corporal-como praxis y hábito-no se comprende en este horizonte. Como dos ramas que se imbrican una a la otra, el discurso higiénico es el marco teórico necesario para entender la importancia de la ejercitación corporal (entendida como el movimiento sistemático y disciplinado del cuerpo) y, a su vez, el ejercicio del cuerpo es la acción necesaria que garantiza su mantenimiento y el éxito de los procesos de aprendizaje en el ámbito escolar.

\section{CONCLUSIONES}

En esta investigación pretendí esbozar algunos de los aspectos vinculados a la introducción e implementación de la cátedra de gimnasia en Vizcaínas, en el periodo de 1875 a 1915. Ciertos elementos han quedado fuera, pero esperan ser retomados en futuras publicaciones fruto de la investigación en curso. La gimnasia se introdujo en los colegios como una disciplina cuyo objetivo -entre otras cosas- fue el de contribuir a la salud corporal y social, así como el de fortalecer e incidir en la educación del cuerpo. En este contexto el cuerpo de las alumnas -en su futuro rol materno- encerró en su interior el porvenir de los nuevos ciudadanos, contribuyendo con la gimnasia al desarrollo físico, moral e intelectual deseable de estos cuerpos femeninos en crecimiento. Lo anterior permite explicar la importancia que ciertos médicos, higienistas y gimnastas otorgaron a la educación de la mujer. Una educación que, como vimos, también fue gimnástica. Es por ello que, nuevamente, hago alusión a esta idea del Colegio como un escaparate de la modernidad porfiriana, en donde el trabajo de la gimnasia sobre el cuerpo fue un signo visible de este proyecto de modernidad.

Considero que el caso del Colegio puede utilizarse como ilustración general del proyecto que una elite profesional y política (y por qué no, higiénico-gimnástica), buscó implementar como la norma general en todos los colegios del país, y en este caso particular, en los colegios de niñas. El caso de Vizcaínas permite ver que la introducción de la gimnasia en el espacio escolar implicó, en un primer momento, la paulatina consolidación de un sistema de lectura y de evaluación del cuerpo de las colegialas y sus movimientos, materia- 
lizado en la asignación de calificaciones y en la implementación de exámenes para este rubro.

En un segundo momento, el estudio de Vizcaínas ayuda a obtener indicios de la formación de profesoras de gimnasia en un periodo en el que la educación física se estaba profesionalizando. La implementación de la gimnasia implicó - particularmente por parte de las alumnas-profesoras- el aprendizaje de una disciplina corporal y de una representación "científica" del funcionamiento del cuerpo humano. Es decir, la práctica gimnástica (acompañada de la materia de higiene) proporcionó a las alumnas más avanzadas un conocimiento del funcionamiento del cuerpo y de la importancia del ejercicio como medida higiénica. Este conocimiento, además, implicó el aprendizaje de una "lectura del cuerpo" y la implementación de movimientos corporales.

Por último y en un tercer momento, el ejercicio gimnástico supuso por parte de las educandas un trabajo personal sobre el cuerpo, cifrado en la adquisición de conocimientos higiénicos, de la ejecución y repetición de movimientos corporales y ejercicios musculares. Ciertos autores han subrayado cómo en este contexto el llamado impulso higienista y la revolución médico-científica contribuyeron a sustituir la moralidad por la salud como modelo del porvenir y la felicidad humana (López Sánchez, 2006, p. 16). Los "profesionales de la medicina asumieron la responsabilidad de fomentar el progreso del país a partir del fortalecimiento de la salud de sus habitantes" (Agostoni, 2006, p. 402). Es posible afirmar que la práctica gimnástica desempeñó aquí un papel central para la consolidación de lo anterior.

Para el año de 1910 la educación física estaba (por lo menos en apariencia) relativamente generalizada en el ámbito escolar y formaba, según lo estipulaban los reglamentos oficiales, parte del programa general de enseñanza de la mayoría de los estados de la república mexicana. Lo anterior es suscrito en los oficios que todos los estados enviaron a la capital, a solicitud del comité que se formó en junio de 1909, para representar a México en el Tercer Congreso Internacional de Higiene Escolar, celebrado en París, en $1910 .^{32}$ El comité, presidido por Justo Sierra, Ezequiel Chávez y Eduardo Liceaga, estaba formado por médicos especialistas, los directores de las escuelas normales y algunos arquitectos. En estos oficios, dicho comité -preparando su participación en el Congreso- solicitó "datos relativos a los progresos que haya alcan-

${ }^{32}$ Representación Mexicana del Tercer Congreso Internacional de Higiene Escolar de junio de 1909a julio de 1910. Caja 274, exp. 19, f. 140. Archivo General de la Nación, México (AGN). 
zado la higiene escolar en los diversos Estados de la Federación”. Los datos se solicitaron mediante un cuestionario, una de las preguntas fue la siguiente: "Datos referentes a la educación física de los alumnos. Escuelas en que se imparte y programas conforme a los cuáles se lleva a cabo". En la mayoría de las respuestas observamos que la educación física se imparte sin mayores contratiempos en las escuelas oficiales de los estados. No obstante, quedan pendientes más estudios que nos muestren las vicisitudes particulares de la implementación y consolidación de la gimnasia en las escuelas mexicanas. El estudio del Colegio de la Paz revela que la introducción de la gimnasia en el espacio escolar no se dio de manera llana, para garantizar su éxito hubo que atender toda una serie de elementos vinculados, entre otras cosas, a la consolidación de una lectura particular del cuerpo y la formación docente. Estos estudios permitirán sopesar si Vizcaínas, dentro de todo, es un caso paradigmático y aislado de la educación que una elite buscó brindarle a las niñas y jóvenes bajo su supervisión. Por lo aquí expuesto Vizcaínas se presenta como el escaparate de un modelo que -atendiendo a las ideas de la época sobre el progreso, la higiene, la civilización, la nación, el cuerpo, la educación, el movimiento y la mujer- buscó ser la pauta general.

\section{LISTA DE REFERENCIAS}

Agostoni, C. (2001). Salud pública y control social en la ciudad de México a fines del siglo xIX. Historia y Grafía, 17, 73-97.

Agostoni, C. (2002). Discurso médico, cultura higiénica y la mujer en la ciudad de México al cambio de siglo (xIX-Xx). Mexican Studies/Estudios Mexicanos, 18(1), 1-22. Dor https://doi.org/10.1525/msem.2002.18.1.1

Agostoni, C. (2006). Imágenes y representaciones de los profesionales de la medicina: entre el público, la ciencia y la prensa. Ciudad de México, 1877-1911. Anuario IEHS, 21, 399-419.

Alvarado, L. (2004). La educación "superior" femenina en el México del siglo XIX. Demanda social y reto gubernamental. México: UNAM.

Amorós (1848). Nouveau manuel complet d'education physique, gymnastique et morale. París: Libraire Encyclopédique de Roret.

Beezley, W. (2004). Judas at the Jockey Club and other episodes of Porfirian Mexico, Lincoln: University of Nebraska Press.

Borja, F. (1856). Elementos de gimnasia. Granada: Imprenta de D. F. Ventura y Sabatel. 
Campo, J. del (1878). Elementos de educación física: descripción de los aparatos considerados más útiles y necesarios para el estudio de la gimnástica: relación detallada de los ejercicios que en los mismos se practican y efectos... llamados a producir en el ser humano. Palma: Imp. de Pedro J. Gelabert.

Carrillo, A. (1999). El inicio de la higiene escolar en México: Congreso Higiénico Pedagógico de 1882. Revista Mexicana de Pediatría, 66(2), 71-74.

Castillo, A. del (2006). Conceptos, imágenes y representaciones de la niñez en la ciudad de México, 1880-1920. México: Instituto Mora/Colmex.

Certeau, Michel de (1993). La escritura de la historia. México: Universidad Iberoamericana.

Chaoul, M. (2012). La higiene escolar en la ciudad de México en los inicios del siglo Xx. Historia Mexicana, LXII(1), 249-304. Recuperado de https://historiamexicana. colmex.mx/index.php/RHM/article/view/205

Chávez, M. (2006). La introducción de la educación física en México: representaciones sobre el género y el cuerpo, 1882-1928. (Tesis de maestría inédita). El Colegio de San Luis, México.

Chávez, M. (2007). Construyendo la nación y el género desde el cuerpo: las prácticas deportivas en la historia de la educación mexicana 1880-1930. Ponencia presentada en el XXVI Congreso de la Asociación Latinoamericana de Sociología, Guadalajara, México.

Chávez, M. (2015). Los orígenes de la educación física en México: reflexiones sobre el cuerpo, el género y la nación. México: RIESLP/Becene/unAM.

Díaz Covarrubias, J. (1875). La instrucción pública en México. Estado que guardan la instrucción primaria, la secundaria y la profesional en la república. Progresos realizados. Mejoras que deben introducirse. México: Imprenta del Gobierno.

Elizalde, F. de (1867). Influencia de la gimnástica en el desarrollo y vigor de la organización del hombre en sus primeras edades. Madrid: Imprenta a cargo de J. E. Morete.

Fraguas, J. (1897). Programa ilustrado de advertencias y figuras de actitudes para las prácticas de la gimnasia higiénica. Madrid: Biblioteca de la Regeneración Física.

Galván Lafarga, L. E. (2017). Aprender en Vizcaínas: de 1767 al siglo xx. En A. R. Valero (coord.), Vizcaínas. 250 años de vida en un colegio a prueba de tiempo (pp. 3751). España: Ediciones el Viso/Colegio de San Ignacio de Loyola, Vizcaínas I.A.P.

Garibay, A. y Teixidor F. (1964). Diccionario Porrúa de historia, biografía y geografía de México. México: Porrúa.

Garrido, M. J. (2014). Peloteros, aficionados y chambones. Historia del juego de pelota de San Camilo y de la educación física en la ciudad de México, 1758-1823, México: Instituto Mora. 
Garrido, M. J. (2016). Para sanar, fortalecer y embellecer los cuerpos. Historia de la gimnasia en la ciudad de México, 1824-1876. México: Instituto Mora.

Gil Mendoza, A. (2010). Génesis de la educación física como disciplina escolar en las escuelas primarias del Estado de México, 1890-1910. Alter. Enfoques Críticos, I(1), 43-57.

Ginzburg, C. (1997). El queso y los gusanos. El cosmos según un molinero del siglo XVI. Barcelona: Muchnik Editores/Océano.

Lladó, J. (1868). Nociones de gimnástica higiénica aplicables a las escuelas de instrucción primaria de uno y otro sexo, con elementos de educación física y de utilidad en todas las edades y para todas las clases de sociedad. Barcelona: Librería de Juan Bastinos e Hijo Editores.

López Sánchez, O. (2006). La mirada médica acerca del cuerpo femenino. Estudio historiográfico de la segunda mitad del siglo xIx mexicano. En M. Cahuich y A. del Castillo (coords.), Conceptos, imágenes y representaciones de la salud y la enfermedad en México, siglos XIX y Xx (pp. 15-41). México: INAH/ENAH.

López Sánchez, O. (2008). La centralidad del útero y sus anexos en las representaciones técnicas del cuerpo femenino en la medicina del siglo xix. En J. Tuñón (comp.), Enjaular los cuerpos. Normativas decimonónicas y feminidad en México (pp. 147-184). México: El Colegio de México.

Martínez del Villar, I. (1881). Tratado de higiene privada y social por Lacassange. Traducido, extractado y modificado de la manera más conveniente por el Dr. Martínez del Villar, para apropiarlo al uso de las Escuelas de Educación Secundaria. México: Antigua Imprenta de Murguía.

Martínez Moctezuma, L. (2011). Historia de la educación física en México. En P. Sharagrodsky (comp.), La invención del "Homo gymnasticus". Fragmentos históricos sobre educación de los cuerpos en movimiento en occidente (pp. 299-320). Argentina: Prometeo.

Memorias del primer Congreso Higiénico-Pedagógico: reunido en la ciudad de México el año de 1882 (1883). México: Imprenta Real del Gobierno.

Meneses Morales, E. (1998). Tendencias educativas oficiales en México: 1821-1911. La problemática de la educación mexicana en el siglo XIX y principios del siglo XX. México: Centro de Estudios Educativos/Universidad Iberoamericana.

Mörner, J. (2001). Memorias de una colegiala. México: Patronato del Colegio de San Ignacio de Loyola (Vizcaínas).

Muriel, J. (1987). Los vascos en México y su colegio de las Vizcaínas. México: gigatam.

Olavarría y Ferrari, E. (1889). Real Colegio de San Ignacio de Loyola, reseña histórica. México: Imprenta de Francisco Díaz de León. 
Ríos Zúñiga, R. y Rosas Íniguez, C. (2011). La Reforma Educativa de Manuel Baranda. Documentos para su estudio (1842-1846). México: IIsUe-UnAm.

Ruiz, L. E. (1888). Nociones elementales de higiene privada. México: Librería de las Escuelas de C. Tamborret.

Saint-Martin, J. y Attali, M. (2016). La historia de la educación física: el ejemplo francés y las perspectivas internacionales de investigación. En L. Martínez Moctezuma (coord.), Formando el cuerpo del ciudadano. Aportes para una historia de la educación física en Latinoamérica (pp. 331-355). México: Universidad Autónoma del Estado de Morelos/Instituto del Deporte y Cultura Física del Estado de Morelos.

Sánchez y González de Somoano, J. (1883). Tratado de gimnasia pedagógica para el uso de las escuelas de primera y segunda enseñanza en institutos. Madrid: Imprenta de M. Minuesa de los Ríos.

Sánchez y González de Somoano, J. (1884). Propaganda gimnástica. Madrid: Imprenta de M. Minuesa de los Ríos.

Staples, A. (2008). Primeros pasos de la higiene escolar decimonónica. En C. Agostoni (coord.), Curar, sanar y educar. Enfermedad y sociedad en México, siglos XIX y XX (pp. 17-42). México: UnAm/BUAP.

Torrebadella-Flix, X. (2018). José Sánchez Somoano: un profesor de educación física escolar entre Madrid y México (1887-1913). Historia y Memoria de la Educación, 8, 549-596. DoI https://doi.org/10.5944/hme.8.2018.19280

Torres Septién, V. (1997). La escuela particular en los primeros años del siglo (1903-1976). México: El Colegio de México/Universidad Iberoamericana.

Vigarello, G. (2005). Corregir el cuerpo. Historia de un poder pedagógico. Buenos Aires: Nueva Visión.

Vigarello, G. y Holt, R. (2005). El cuerpo cultivado: gimnastas y deportistas en el siglo XIX. En A. Corbin, J. Courtine y G. Vigarello (dirs.), Historia del cuerpo (pp. 295-354). España: Taurus.

\section{OTRAS FUENTES}

Archivos

AGN Archivo General de la Nación México, México.

Aнjmbn Archivo Histórico José María Basagoiti Noriega, del Colegio de las Vizcaínas, México. 